\title{
ANTIPSYCHOTICS AND LOW VITAMIN D - ADDITIONAL DATA CALLING FOR DRUG CAUSALITY ASSESSMENT
}

\author{
SVETLANA RISTIC ${ }^{1}$, DRAGAN MILOVANOVIC ${ }^{2,6 *}$, VLADIMIR JANJIC ${ }^{3,6}$, \\ MARIJANA STANOJEVIC PIRKOVIC ${ }^{4,6}$, IVANA SIMIC VUKOMANOVIC ${ }^{5,7}$, \\ SVETLANA CURCIC ${ }^{8}$ and SANJA KOCIC ${ }^{5,7}$
}

${ }^{1}$ Institute for Oncology and Radiology of Serbia, Department of Epidemiology and Prevention, Belgrade, Serbia

${ }^{2}$ Department of Pharmacology and Toxicology, ${ }^{3}$ Department of Psychiatry,

${ }^{4}$ Department of Biochemistry, ${ }^{5}$ Department of Social Medicine, Faculty of Medical Sciences,

University of Kragujevac, Serbia

${ }^{6}$ Clinical Centre "Kragujevac", Kragujevac, Serbia

${ }^{7}$ Institute for Public Health Kragujevac, Serbia

${ }^{8}$ Faculty of Education in Jagodina, University of Kragujevac, Serbia

The recent systematic published findings suggest that patients with psychiatric disorders have an increased risk for lower serum vitamin D levels (1). However, the exact causes of this phenomenon and its relevance for clinical outcomes have not been fully explained yet. The population-level data suggest that there is a positive correlation between optimal serum levels of $25(\mathrm{OH}) \mathrm{D}$ and better mental health indicators (2). In addition, active vitamin D supplementation shows some improvements in the symptoms. However, it did not affect the course of psychosis in patients with chronic, antipsychotictreated disease in double-blind, placebo-controlled clinical trial settings (3).

Antipsychotics could affect calcium, magnesium, phosphorous and $25(\mathrm{OH}) \mathrm{D}$ serum concentrations during treatment initiations as well as during dosage or drug changes (4). Disturbances in minerals and vitamins related to bone metabolism can lead to increased risks for fractures associated with the use of the first and the second generation of antipsychotic medication as was documented in a recent meta-analysis of the available data (5). However, the evidence base for a definite assessment of the possible causality relations between vitamin D disturbances and antipsychotic drugs remains insufficient. In addition, vitamin D levels and bone health may be under the effect of concomitant psychotropic drugs affecting vitamin D metabolism such as mood stabilizers (6). Therefore, this study aimed at exploring $25(\mathrm{OH}) \mathrm{D}$ serum levels in patients with psychoses who take antipsychotics in comparison to healthy individuals, with limited benzodiazepines allowed as concomitant psychotropics in order to control their possible side-effects.

The study had a cross-sectional design and, besides blood testing for measuring vitamin D levels, it followed the observational approach. The Ethics Committee of the Clinical Centre "Kragujevac", Kragujevac, Serbia, approved the research and all subjects signed the informed consent for participation in the study. The study sites included the departments of psychiatry, clinical biochemistry and clinical pharmacology of the hospital.

Our previous research provided the basis for sample size calculation data about the proposed significance between group difference of $25(\mathrm{OH})$ serum concentrations and their variability (7). Using appropriate software (www.gpower.hhu.de), with alpha $=0.05$, study power of 0.8 and other necessary inputs as well as the corrective increase for presumed non-parametric data distribution we estimated total study sample of at least 50 people, 25 in each group. We finally included a total of 56 adult subjects of both genders who were allocated to two groups: 26 patients with mental illnesses taking

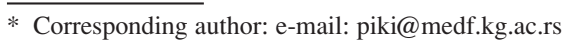


antipsychotic medication (the experimental group) and 30 healthy individuals (the control group). The patients had only one diagnosis from the group of psychotic disorders (World Health Organization International Classification of Diseases version 10, codes F20). The antipsychotic drugs had been the foundation of the treatment with only limited uses of benzodiazepines allowed to enhance sedative, anxiolytic effects. The use of antidepressants, mood stabilizers, cognitive enhancers, and other psychotropic drugs was an exclusion criterion. The drug treatment for a concomitant somatic disease in stable phases or stages was allowed within both study groups.
The semi-structured questionnaire for the assessment of vitamin D status was designed based on the previous studies in the field and the study was conducted within the same geographical area (7-8). Other data were extracted from the patients' medical files or were obtained through an interview in case of healthy subjects. The blood samples were obtained from May to June 2016 which is a season with adequate and approximately the same sunshine exposure. The serums were sent to the hospital laboratory where the vitamin $\mathrm{D}$ (in $25(\mathrm{OH}) \mathrm{D}$ form), calcium, phosphorus, magnesium, sodium, and potassium concentrations were determined by using

Table 1. Characteristics of study subjects and the status of vitamin D and bone minerals.

\begin{tabular}{|c|c|c|c|}
\hline Variable & $\begin{array}{l}\text { Antipsychotic group } \\
(\mathrm{n}=26)\end{array}$ & $\begin{array}{l}\text { Control group } \\
(\mathrm{n}=30)\end{array}$ & Statistics \\
\hline Male gender & $12(46.2)$ & $12(40.0)$ & $\mathrm{p}=0.642$ \\
\hline Age (years) & $50.4(11.9)$ & $49.2(14.6)$ & $\mathrm{p}=0.986$ \\
\hline Body mass index $\left(\mathrm{kg} / \mathrm{m}^{2}\right)$ & $25.3(4.3)$ & $25.7(4.0)$ & $\mathrm{p}=0.925$ \\
\hline Urban inhabitancy & $21(80.8)$ & $30(100)$ & $\mathrm{p}=0.017$ \\
\hline Higher education* & $3(11.5)$ & $20(66.7)$ & $\mathrm{p}<0.001$ \\
\hline Good life condition* & $6(23.1)$ & $30(100)$ & $\mathrm{p}<0.001$ \\
\hline Smoking & $18(69.2)$ & $9(30)$ & $\mathrm{p}=0.008$ \\
\hline Coffee consumption & $13(50.0)$ & $5(16.7)$ & $\mathrm{p}=0.012$ \\
\hline Physical activity & $13(50.0)$ & $30(100)$ & $\mathrm{p}<0.001$ \\
\hline Sedentary life-style & $20(76.9)$ & $0(0)$ & $\mathrm{p}<0.001$ \\
\hline Meat consumers & $22(84.6)$ & $30(100)$ & $\mathrm{p}=0.040$ \\
\hline Fish consumers & $13(50.0)$ & $27(90.0)$ & $\mathrm{p}=0.001$ \\
\hline Eggs consumers & $24(92.3)$ & $19(63.3)$ & $\mathrm{p}=0.012$ \\
\hline Bread consumption (g/day) & $341.7(158.6)$ & $185.8(151.9)$ & $\mathrm{p}<0.001$ \\
\hline Sun exposure $(>60 \mathrm{~min} / \text { day })^{*}$ & $9(34.6)$ & $15(50.0)$ & $\mathrm{p}=0.031$ \\
\hline Arterial hypertension & $5(19.2)$ & $6(20.0)$ & $\mathrm{p}=0.942$ \\
\hline Previous bone fracture & $0(0)$ & $1(3.3)$ & $\mathrm{p}=1.000$ \\
\hline Serum $25(\mathrm{OH}) \mathrm{D}(\mathrm{ng} / \mathrm{mL})^{1}$ & $11.2(8.0,8.4,2.9,30.4)$ & $19.4(9.1,15.8,7.6,43.6)$ & $\mathrm{p}<0.001$ \\
\hline $\begin{array}{l}\text { Deficiency/ Insufficiency/ } \\
\text { Sufficiency of vitamin D }\end{array}$ & $22(84.6) / 3(11.5) / 1(3.9)$ & $19(63.3) / 5(16.7) / 6(20.0)$ & $\mathrm{p}=0.128$ \\
\hline $\begin{array}{l}\text { Serum } 25(\mathrm{OH}) \mathrm{D} \text { in patients } \\
\text { with deficiency }(\mathrm{ng} / \mathrm{mL})^{1}\end{array}$ & $8.4(4.4,8.1,2.9,19.1)$ & $13.7(3.2,13.8,7.6,19.4)$ & $\mathrm{p}<0.001$ \\
\hline $\begin{array}{l}\text { Serum } 25(\mathrm{OH}) \mathrm{D} \text { in patients } \\
\text { with insufficiency }(\mathrm{ng} / \mathrm{mL})^{1}\end{array}$ & $25.7(3.8,27.3,21.4,28.4)$ & $22.4(1.4,22.2,20.9,24.6)$ & $\mathrm{p}=0.393$ \\
\hline $\begin{array}{l}\text { Serum } 25(\mathrm{OH}) \mathrm{D} \text { in patients } \\
\text { with sufficiency }(\mathrm{ng} / \mathrm{mL})^{1}\end{array}$ & 30.4 (n.a.) & $34.9(4.9,33.8,30.6,43.6)$ & $\mathrm{p}=0.286$ \\
\hline Serum calcium $(\mathrm{mmol} / \mathrm{L})^{2}$ & $2.40(0.12)$ & $2.40(0.11)$ & $\mathrm{p}=0.859$ \\
\hline Serum magnesium $(\mathrm{mmol} / \mathrm{L})^{2}$ & $0.79(0.11)$ & $0.90(0.05)$ & $\mathrm{p}<0.001$ \\
\hline Serum phosphorous $(\mathrm{mmol} / \mathrm{L})^{2}$ & $1.08(0.25)$ & $1.11(0.17)$ & $\mathrm{p}=0.896$ \\
\hline
\end{tabular}

Numbers represent the frequency (percent), ${ }^{1}$ the mean (standard deviation, median, minimum, maximum) and ${ }^{2}$ the mean (standard deviation); $* 2$ categories: n.a.-not applicable, due to a single observation 


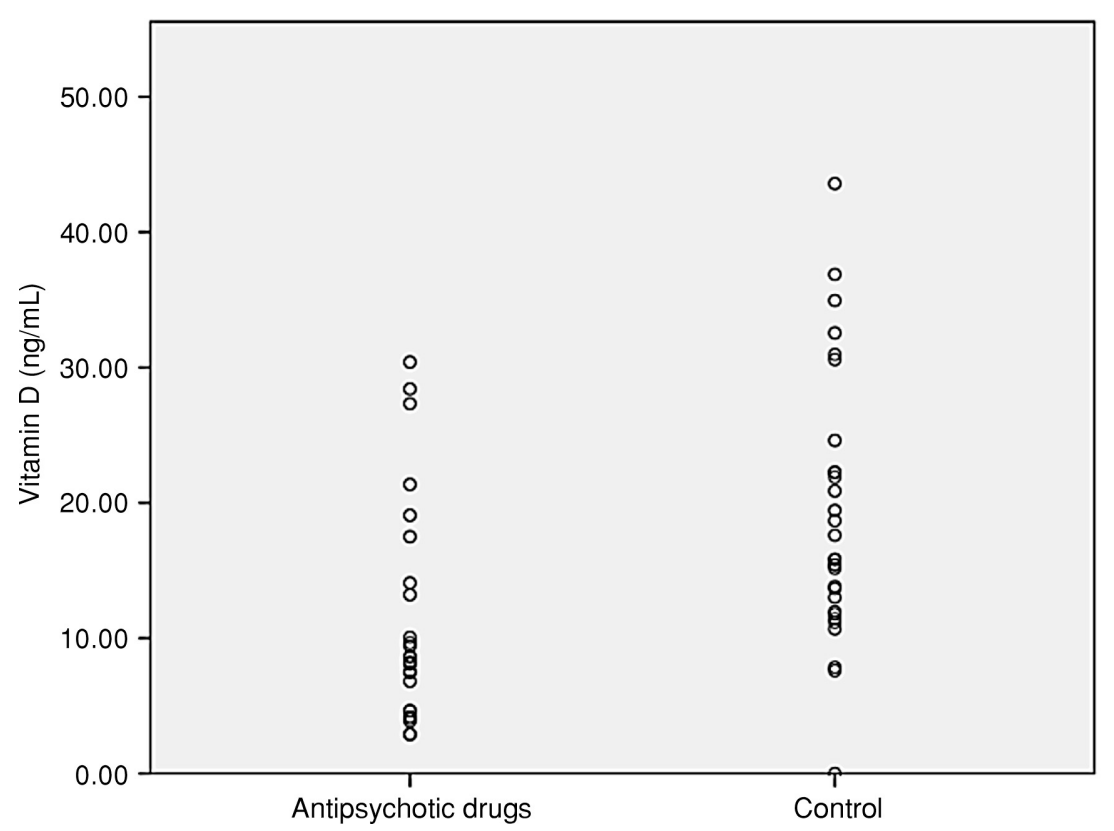

Figure 1. The serum concentrations of $25(\mathrm{OH}) \mathrm{D}$ in patients taking antipsychotic drugs $(\mathrm{n}=26)$ and in healthy, control subjects $(\mathrm{n}=30)$

"Cobas e601" analyzer (Roche Diagnostics, Mannheim, Germany) and "Beckman Coulter AU 680" biochemical analyzers, as appropriate. Vitamin D measurements were performed using the manufacturer's reagent testing kit (electrochemiluminescence binding assay), providing regular internal and external controls according to the laboratory quality assurance procedures.

The vitamin D status types were defined as: deficiency $(<20 \mathrm{ng} / \mathrm{mL})$, insufficiency (20-29.9 $\mathrm{ng} / \mathrm{mL}$ ) and sufficiency (>30 ng/mL) (9). Statistical analyses of collected data included testing of sample distribution for normality (Normal Q-Q Plot, Histogram, Kolmogorov-Smirnov test, ShapiroWilk test), the measures of descriptive statistics as well as Wilcoxon rank sum test, Pearson $\mathrm{c}^{2}$ test and Fisher exact test for analysing the differences between study groups. The level of probability for statistical significance was established at $\mathrm{p}<0.05$. Data processing and analysis were done in the statistical program R - version 3.1.1 (2014-07-10). Demographic and other clinical variables in study subjects are presented in detail in Table 1. There were 16 inpatients and 10 outpatients in the antipsychotic group. The mean duration of their primary mental illness was 15.7 (9.5) years (median 18, range 1-35). The most frequently prescribed antipsychotic drug was haloperidol (in 16 patients) followed by clozapine (7), olanzapine (7), risperidone (5), chlorpromazine (3), fluphenazine (2) and aripiprazole (1). The mean number of antipsychotic drugs per patient was 1.6 (from 1 to 3 ). Only allowed concomitant psychotropic medications in patients included benzodiazepines and similar drugs such as lorazepam (in 14 patients), zolpidem (7), diazepam (5), bromazepam (2) and midazolam (2). The arterial hypertension was the most frequent somatic disease in subjects of both study groups and other chronic illnesses were diabetes mellitus type 2 in three patients with psychosis and thyroid disease and osteoporosis in two healthy subjects.

The analysis of the data confirmed that there was a statistically significant difference between study groups in vitamin D serum concentrations (Figure 1) (Table 1). The patients taking antipsychotics had significantly lower vitamin D serum levels than healthy subjects, in both the overall study sample $(\mathrm{n}=56, \mathrm{p}<0.001)$ and the subgroup of people with the deficiency $(n=41, p<0.001)$. Some socio-demographic and most of the habitual and dietary characteristics that might directly or indirectly impact vitamin D status were statistically different between the study groups (Table 1). However, a multivariable analysis was not performed due to the limited sample size.

The results presented in this paper in addition to other reliable evidence confirm that individuals suffering from psychotic disorders who take antipsychotic drugs are a vulnerable population group for developing inadequate vitamin D serum 
concentrations. The patients who participated in our study used benzodiazepines but we are currently unaware of any valid data about the possible influence of this drug class on vitamin D metabolism in humans. Some subjects took antihypertensive medications but the proportion of people with arterial hypertension was small and almost the same in both study groups. Therefore, if the drugs contribute to lower serum levels of $25(\mathrm{OH}) \mathrm{D}$ their impact was present in both study groups so antipsychotics remain the only agents for the causative consideration.

On the other hand, our study notes significant differences between the study groups in some lifestyle and dietary habits which could influence vitamin D status. Our previous research has proved that the use of clozapine increases the risk for vitamin D deficiency and that physical activity, exercising and vitamin D-reach food have a protective role (10). A serious or insufficiently controlled psychotic illness is very likely associated with poor socio-economic status and lifestyle habits which alone increase the risk for vitamin D disturbances. However, only a few among the numerous factors investigated in the previously published studies unambiguously correlate with vitamin D levels in people with psychosis (1). Moreover, the evidence about the significance of vitamin D status for normal brain development and functions has accumulated over the years (11-12). The novel study has revealed that low vitamin D blood levels are associated with outbreaks of the first schizophrenia episodes (13). Therefore, vitamin D deficiency could either precede or contribute (or both) to the structural brain damage and functional neuronal disturbances which occur in patients with psychotic illnesses (14).

In our study the serum $25(\mathrm{OH}) \mathrm{D}$ concentrations were, in general, low in both the patients and the control subjects. The design of our research precluded a more comprehensive analysis for providing the answer to why many healthy people in our research did not have sufficient vitamin D serum levels during the sunshine period. According to our knowledge, there were no studies published in recent years which investigated $25(\mathrm{OH}) \mathrm{D}$ serum concentrations in our country in order to reveal the current vitamin D status for healthy people in a large sample. Yet, some studies which included the postmenopausal women and the students, measuring $25(\mathrm{OH}) \mathrm{D}$ serum concentrations during sunshine months, also found a very high frequency of vitamin D deficiency in those, apparently healthy subjects $(15,16)$. Nevertheless, we are unable to make any conclusion about vitamin D status on the population level at present as the matter was outside the scope of our research.
The inability of proving the causal relationships between antipsychotic use and vitamin D deficiency probably constitutes one of the major limitations of our study. Other investigators in the field also used comparative, cross-sectional design for explorative purposes of vitamin D status in the diseased and the healthy people; however, well-known methodological weaknesses of this study type precludes more sound conclusion about the causality at the moment $(17,18)$. This issue and other possible study limitations (e.g. role of putative, confounders and their interactions with individual antipsychotics) have to be addressed in further investigations.

In conclusion, patients with psychoses taking antipsychotics have, in comparison with healthy individuals, a higher probability for inadequate serum levels of $25(\mathrm{OH}) \mathrm{D}$. However, the true nature of the relations between the disease, disturbances, antipsychotic drugs, and other plausible contributors are currently unknown. Taking into account the significance and the scope of medical and public health issues related to mental disorders, the further research into nutrition and pharmacotherapy is needed in near future in order to finally resolve the issues of potential drug causalities.

\section{Acknowledgments}

Authors thank the Faculty of Medical Science University of Kragujevac for the support with the junior research grant JP 13-14.

\section{Conflict of interest}

All authors have no conflicts of interest.

\section{REFERENCES}

1. Adamson J., Lally J., Gaughran F., Krivoy A., Allen L. at al.: Psychiatry Res. 249, 78 (2017).

2. Chu F., Ohinmaa A., Klarenbach S., Wong Z.W., Veugelers P.: Nutrients 9, 1116 (2017).

3. Krivoy A., Onn R., Vilner Y., Hochman E., Weizman S. at al.: EBioMedicine 26, 138 (2017).

4. Milovanovic D.R., Stanojevic Pirkovic M., Zivancevic Simonovic S., Matovic M., Djukic Dejanovic S. at al.: Psychiatry Investig. 13, 89 (2016).

5. Lee S.H., Hsu W.T., Lai C.C., Esmaily-Fard A., Tsai Y.W. at al.: Osteoporos. Int. 28, 1167 (2017).

6. Hategan A., Bourgeois J.A.: Psychosomatics 54, 606 (2013). 
7. Stanojević Pirković M.: Risk factors for disturbances of bone tissue homeostasis in patients with psychotic disorders, PhD Thesis, Faculty of Medical Sciences University of Kragujevac, Kragujevac (in Serbian) 2012.

8. Milovanovic O.: Population pharmacokinetics of 25-hydroxyvitamin $\mathrm{D}$ in students, $\mathrm{PhD}$ Thesis, Faculty of Medical Sciences University of Kragujevac, Kragujevac (in Serbian) 2014.

9. Holick M.F., Binkley N.C., Bischoff-Ferrari H.A., Gordon C.M., Hanley D.A. et al.: J. Clin. Endocrinol. Metab. 96, 1911 (2011).

10. Ristic S., Zivanovic S., Milovanovic D.R., Janjic V., Djokovic D. et al.: J. Nutr. Sci. Vitaminol. 63, 85 (2017).

11. Cui X., Gooch H., Petty A., McGrath J.J., Eyles D.: Mol. Cell. Endocrinol. 453, 131 (2017).
12. Anjum I., Jaffery S.S., Fayyaz M., Samoo Z., Anjum S.: Cureus 10, e2960 (2018).

13. Firth J., Carney R., Stubbs B., Teasdale S.B., Vancampfort D. et al.: Schizophr. Bull. 44, 1275 (2018).

14. Kočovská E., Gaughran F., Krivoy A., Meier U.C.: Psychiatry 8, 47 (2017).

15. Vuceljic M., Ilic-Stojanovic O., Lazovic M., Grajic M.: Vojnosanit Pregl. 69, 243 (2012).

16. Milovanovic O.Z., Milovanovic J.R., Djukic A., Matovic M., Lucic A.T. et al.: Acta Pol. Pharm. 72, 213 (2015).

17. Workineh M., Mathewos B., Moges B., Gize A., Getie S. et al.: Arch. Public Health 75, 25 (2017).

18. Grimes D.A., Schulz K.F.: Lancet 359, 145 (2002).

Received: 18.11 .2018 